\title{
Effect of morphological changes in feather follicles of chicken carcasses after defeathering and chilling on the degree of skin contamination by Campylobacter species
}

\author{
Khin Maung LATT ${ }^{1,2) \#, ~ A y a k a ~ U R A T A ~}{ }^{1) \#}$, Taisuke SHINKI ${ }^{1)}$, Satomi SASAKI ${ }^{1)}$, \\ Takako TANIGUCHI) and Naoaki MISAWA ${ }^{1-3) *}$ \\ 1)Laboratory of Veterinary Public Health, Department of Veterinary Medical Science, Faculty of Agriculture, \\ University of Miyazaki, Miyazaki, 1-1 Gakuenkibanadai-nishi, Miyazaki 889-2192, Japan \\ 2)Interdisciplinary Graduate School of Medicine and Veterinary Medicine, University of Miyazaki, 5200 Kihara, \\ Kiyotake-cho, Miyazaki 889-1692, Japan \\ ${ }^{3)}$ Center for Animal Disease Control, University of Miyazaki, Miyazaki, 1-1 Gakuenkibanadai-nishi, Miyazaki \\ 889-2192, Japan
}

J. Vet. Med. Sci.

80(1): 49-54, 2018

doi: $10.1292 /$ jvms.17-0534

Received: 30 September 2017 Accepted: 6 November 2017 Published online in J-STAGE: 20 November 2017
ABSTRACT. Campylobacter jejuni and C. coli are the leading causes of enteric infections in many developed countries. Healthy chickens are considered to act as reservoirs of campylobacters, as the organisms colonize the intestinal tract. Once infected birds enter a processing plant, contamination of chicken carcasses with campylobacters occurs over the entire skin during defeathering and evisceration due to leakage of crop and/or intestinal contents. Although the role of feather follicles in the contamination of chicken carcasses by campylobacters during processing is still debatable, it has been considered that the microorganisms would be entrapped and retained in the follicles due to the morphological changes resulting from defeathering and chilling. In the present study, we observed the morphology of feather follicles in chicken carcasses after defeathering and chilling. A total of 3,133 feather follicles were examined for morphological changes before and after chilling. Shortly after defeathering, most (91.5\%) of the follicles were closed, whereas after chilling they were either closed (85.5\%) or open (6\%), although a small proportion of enlarged follicles became smaller or closed (2.6\%). Moreover, $5.9 \%$ of the follicles that were slightly open became further enlarged after chilling. Furthermore, the proportion of enlarged feather follicles that became closed after chilling showed no discernible relationship with the degree of campylobacter contamination in different areas of the carcass skin, suggesting that campylobacters may not be confined to feather follicles as a result of the morphological changes attributable to defeathering and chilling.

KEY WORDS: Campylobacter, chicken carcass, contamination, feather follicle

Campylobacter jejuni and C. coli are the leading causes of enteric infections in many developed countries, and the public health burden due to campylobacteriosis is increasing [16]. Although many risk factors for Campylobacter transmission have been identified $[10,14]$, it is considered that the handling and consumption of poultry meat are the most important source of human campylobacteriosis [7, 9]. The epidemiological data for Japan are based on passive surveillance, but approximately 2,000 cases per year have been reported as foodborne infections since 1982 [8]. Since there is a preference in Japan for fresh raw "free-range" chicken meat and liver, this is likely to account for most cases of human campylobacteriosis.

Healthy chickens are considered to act as reservoirs of campylobacters, as the organisms colonize the intestinal tract. Once chickens enter a processing plant, contamination of the carcasses with $C$. jejuni and $C$. coli occurs over the entire skin during the defeathering and evisceration process due to expulsion and/or leakage of crop and intestinal contents $[2,12,13,15]$. Berndtson et al. have demonstrated another possible mechanism of contamination, having isolated $C$. jejuni from subcutaneous scrapings of chicken carcasses, indicating that the organisms can reside in feather follicles [1]. They suggested that the scalding and defeathering procedures allow feather follicles to open, and that subsequent low-temperature chilling then closes the follicles again,

*Correspondence to: Misawa, N.: a0d901u@cc.miyazaki-u.ac.jp \#These authors contributed equally to this work. O2018 The Japanese Society of Veterinary Science

This is an open-access article distributed under the terms of the Creative Commons Attribution Non-Commercial No Derivatives (by-nc-nd) License. (CC-BY-NC-ND 4.0: https://creativecommons.org/licenses/by-nc-nd/4.0/) 
thus trapping the microorganisms within them. However, the morphological changes in feather follicles in response to temperature during carcass processing have not been examined in detail. In the present study, we investigated the morphology of feather follicles in chicken carcasses after defeathering and chilling, and examined whether these morphological changes might play an important role in campylobacter contamination.

\section{MATERIALS AND METHODS}

\section{Chicken carcasses}

The present survey was conducted from May to July, 2011, at a processing plant in Miyazaki prefecture handling about 400-500 free-range chickens daily. A total of 15 4-5-month-old carcasses of both sexes were investigated after defeathering. After bleeding and scalding at $62^{\circ} \mathrm{C}$ for $80 \mathrm{sec}$, the carcasses were moved to a tank for defeathering using rubber fingers together with rotation in flowing tap water at $20^{\circ} \mathrm{C}$ for $70 \mathrm{sec}$. Then the carcasses were moved immediately in a chiller tank before evisceration.

\section{Morphological observation of feather follicles}

To observe the morphology of feather follicles after defeathering and after chilling of carcasses, different parts of the skin were photographed. To obtain photographs taken at the same angle after defeathering and after chilling, each part of the skin was marked with both sewing pins with a head $(1 \mathrm{~cm}$ diameter) and branding with a heated iron. The following parts of the skin (with the number of feather follicles examined) were photographed: dorsal neck $(\mathrm{n}=960)$, abdominal region $(\mathrm{n}=851)$, thigh $(\mathrm{n}=684)$, back $(n=391)$ and crotch $(n=247)$. The chicken carcasses were then chilled in $15 l$ of ice water for 90 min. The subcutaneous temperature in the abdominal region was monitored using a digital thermometer (Sato Keiryoki MFG, Tokyo, Japan) during chilling, and each carcass was examined when the temperature had fallen below $8^{\circ} \mathrm{C}$. After chilling, the same parts of the marked skin were photographed again from the same angle. A total of 3,133 feather follicles were examined for morphological changes after defeathering and after chilling. The areas of the feather follicles were measured using image analysis software (ImageJ, National Institutes of Health, Bethesda, MD, U.S.A., http://imagej.nih.gov/ij/) based on the diameter of the pin's head as a reference scale, and the area of each follicle after defeathering and after chilling was compared.

\section{Enumeration of Campylobacter species naturally contaminating chicken skin after chilling}

The number of contaminating campylobacter cells was determined by the most-probable-number (MPN) method. Ten-gram sample of skin from each of the dorsal neck, abdominal region, back, and thigh was removed after chilling from 3 chicken carcasses and a 10 -fold serial dilution of each skin specimen $\left(10^{-1}\right.$ to $\left.10^{-3}\right)$ was made in Preston enrichment medium (Oxoid, Basingstoke, U.K.) after homogenized using a stomacher for $90 \mathrm{sec}$. The samples were cultured at $37^{\circ} \mathrm{C}$ for $48 \mathrm{hr}$ under microaerophilic conditions $\left(80 \% \mathrm{~N}_{2}, 10 \% \mathrm{CO}_{2}, 5 \% \mathrm{O}_{2}\right.$ and $\left.5 \% \mathrm{H}_{2}\right)$, and then one loopful of each dilution was transferred to modified Cefoperazone Charcoal Deoxycholate agar (mCCDA; Oxoid CM0739) supplemented with CCDA selective supplement (Oxoid SR0155) for isolation. The number of campylobacter cells was calculated by applying the common 3-tube MPN procedure based on the number of bacterial colonies indicating PCR-positivity for campylobacter at each dilution. The specific PCR reactions for Campylobacter spp. were performed as described elsewhere [17].

\section{Statistical analysis}

The areas of feather follicles after feathering and after chilling were compared, and Campylobacter counts for different areas of chicken skin were compared by Fisher's exact two-tailed test using R version 3.1.3 (R Foundation for Statistical Computing, Vienna, Austria). Statistical significance was defined as $P<0.05$.

\section{RESULTS}

\section{Kinetics of subcutaneous temperature in carcasses after chilling}

Three chicken carcasses were immersed in chilled water at $3.0^{\circ} \mathrm{C}$, and the subcutaneous temperature was measured for 90 min. The initial mean temperature of the carcasses was $35.1^{\circ} \mathrm{C}$ and then gradually decreased with time (Fig. 1). The temperature of the carcasses fell below $8^{\circ} \mathrm{C}$ after $60 \mathrm{~min}$ of chilling, and this temperature was maintained until $90 \mathrm{~min}$.

\section{Morphological changes in feather follicles after defeathering and chilling}

Based on the mean area of feather follicles after defeathering and chilling, 4 types of morphological changes were observed: i) closed $\rightarrow$ open, ii) slightly open $\rightarrow$ enlarged, iii) open $\rightarrow$ smaller or closed, and iv) closed $\rightarrow$ closed. The area of all closed follicles was considered to be zero. The "slightly open $\rightarrow$ enlarged " type was defined as a feather follicle with an area of more than zero after defeathering, and becomming larger after chilling. The "open $\rightarrow$ smaller or closed" type was defined as a feather follicle with an area of more than zero after defeathering, and becoming smaller or closed after chilling. Shortly after defeathering, most (91.5\%) of the follicles were closed, whereas after chilling they were either closed (85.5\%) or open (6\%), although a small proportion of enlarged follicles became smaller or closed (2.6\%). Moreover, $5.9 \%$ of the follicles that were slightly open became further enlarged after chilling (Table 1 and Fig. 2). 


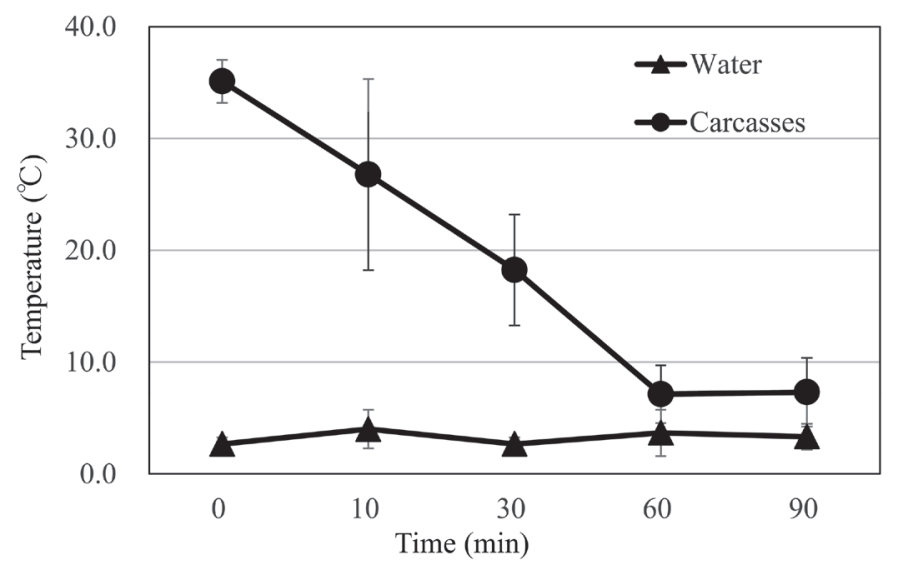

Fig. 1. Temperature kinetics (mean value $\pm \mathrm{SD}$ ) in the subcutaneous region of 3 carcasses after chilling.

Table 1. Morphological changes in feather follicles after defeathering and chilling

\begin{tabular}{|c|c|c|c|c|c|}
\hline \multirow[b]{2}{*}{ Skin region } & \multirow[b]{2}{*}{$\begin{array}{l}\text { No. of } \\
\text { follicles } \\
\text { examined }\end{array}$} & \multicolumn{4}{|c|}{ No. of morphological changes ${ }^{a)}(\%)$} \\
\hline & & $\begin{array}{c}\text { Closed } \\
\downarrow \\
\text { Open }\end{array}$ & $\begin{array}{c}\text { Slightly open } \\
\downarrow \\
\text { Enlarged }\end{array}$ & $\begin{array}{c}\text { Open } \\
\downarrow \\
\text { Smaller or Closed }\end{array}$ & $\begin{array}{c}\text { Closed } \\
\downarrow \\
\text { Closed }\end{array}$ \\
\hline Dorsal neck & 960 & $45(4.7)$ & $13(1.4)$ & $5(0.5)$ & $897(93.4)$ \\
\hline Abdominal & 851 & $84(9.9)$ & $74(8.7)$ & $49(5.7)$ & $644(75.7)$ \\
\hline Thigh & 684 & $28(4.1)$ & $12(1.7)$ & $8(1.2)$ & $636(93.0)$ \\
\hline Back & 391 & $28(7.2)$ & $22(5.6)$ & $7(1.8)$ & $334(85.4)$ \\
\hline Crotch & 247 & $2(0.8)$ & $63(25.5)$ & $14(5.7)$ & $168(68.0)$ \\
\hline Total & 3,133 & $187(6.0)$ & $184(5.9)$ & $83(2.6)$ & $2,679(85.5)$ \\
\hline
\end{tabular}

a) The area of all closed follicles is considered to be zero. The "slightly open $\rightarrow$ enlarged" type is defined as a feather follicle with an area of more than zero after defeathering, and becoming larger after chilling. The "open $\rightarrow$ smaller or closed" type is defined as a feather follicle with an area of more than zero after defeathering, and becoming smaller or closed after chilling.

\section{Area of feather follicles after defeathering and chilling}

Figure 3 shows the area of feather follicles after defeathering and chilling, omitting data for feather follicles that remained closed regardless of the processing steps. Compared to the mean area of feather follicles after each processing, the values after chilling were larger than those after defeathering for all of the skin regions examined.

\section{Enumeration of Campylobacter spp. in different regions of carcass skin}

The average counts of Campylobacter spp. from skin samples of the neck, abdominal region, back, and thigh were 0.79, 0.30 , 0.78 and $0.30 \log$ cfu/ $10 \mathrm{~g}$, respectively (Fig. 4). The proportions of enlarged follicles that became closed in these skin areas after chilling were $0.52,5.76,1.79$ and $1.17 \%$, respectively. Although follicles in abdominal skin showed the highest proportion of closure (5.76\%), the average count of Campylobacter spp. naturally contaminating the skin was the lowest in this region (0.30 log $\mathrm{cfu} / 10 \mathrm{~g})$.

\section{DISCUSSION}

As chicken carcasses are processed together with skin, the problem of microorganism control is well known [6]. Once organisms become attached to the skin surface, the effectiveness of disinfectant may be low, although data from various studies have been conflicting [11]. Moreover, the skin surface has many crevices or folds, and these areas may be difficult to decontaminate using disinfectants.

Berndtson et al. [1] demonstrated that Campylobacter spp. could be isolated from feather follicles by scraping samples of subcutaneous skin. They considered that feather follicles open after picking but then become closed when low-temperature chilling is performed, thus trapping campylobacter species within them. Since then, it has been considered that feather follicles play an important role in the bacterial contamination of chicken carcasses. However, Buhr et al. pointed out that as the samples examined were taken only after chilling, it was uncertain whether bacteria entered the follicles during defeathering or migrated into the skin while being chilled in water [3]. 


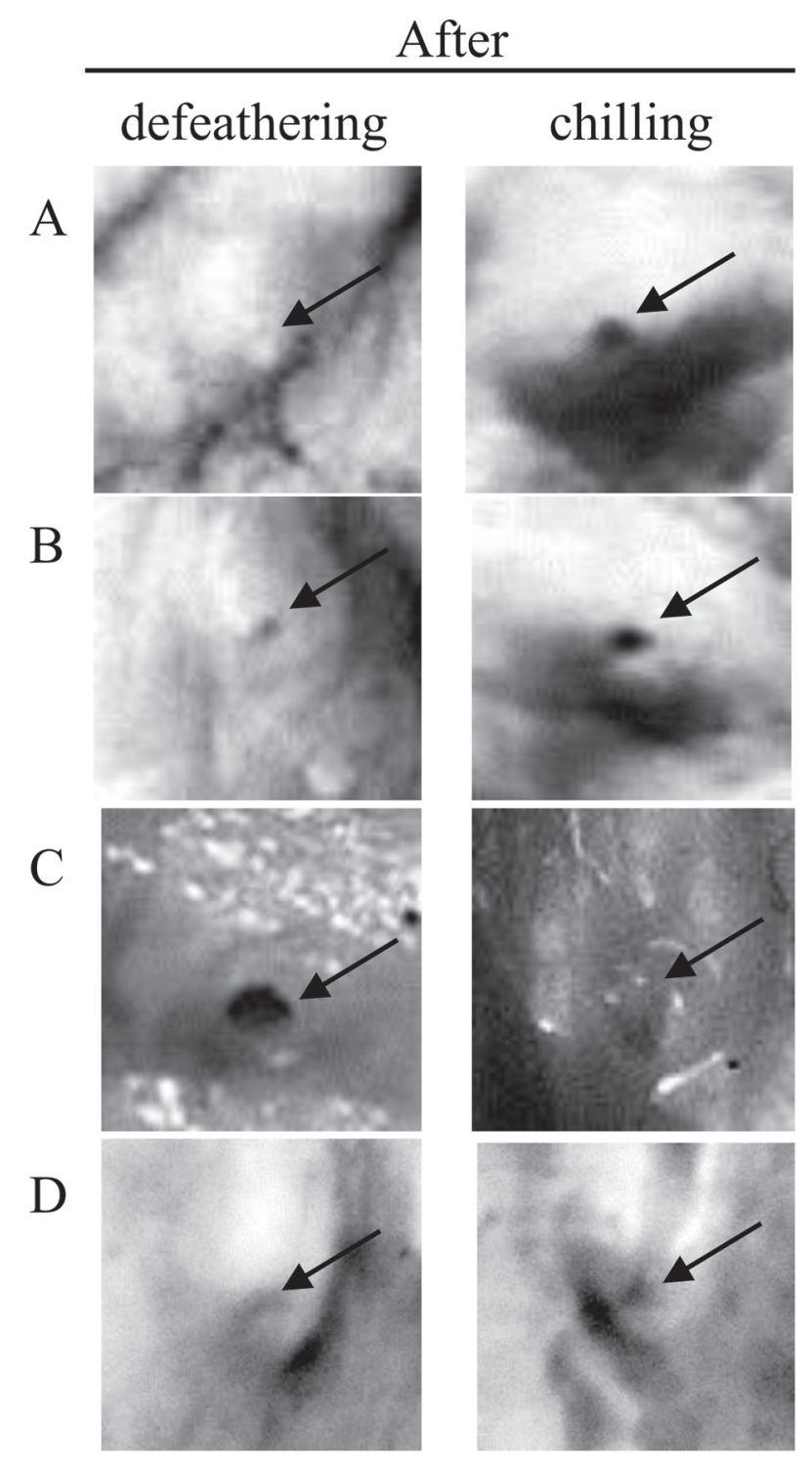

Fig. 2. Morphological changes in feather follicles examined after defeathering and chilling. Based on the mean area of feather follicles after defeathering and chilling, representative 4 types of morphological changes are photographed: (A) closed $\rightarrow$ open, (B) slightly open $\rightarrow$ enlarged, (C) open $\rightarrow$ smaller or closed, and (D) closed $\rightarrow$ closed. The area of all closed follicles is considered to be zero. The "slightly open $\rightarrow$ enlarged" type is defined as a feather follicle with an area of more than zero after defeathering, and becoming larger after chilling. The "open $\rightarrow$ smaller" type is defined as a feather follicle with an area of more than zero after defeathering, and becoming smaller or closed after chilling.

To clarify the role of feather follicles in bacterial contamination of chicken carcasses, Cason and colleagues performed a comparative study using genetically feathered and featherless broiler chickens [4]. They found no significant differences between the feathered and featherless broilers in terms of the numbers of aerobic bacteria, Escherichia coli, and Campylobacter jejuni in rinsed carcass samples immediately after defeathering, suggesting that feather follicles may make only a minor contribution to bacterial contamination.

In the present study, we observed morphological changes in feather follicles of chicken carcasses after scalding and chilling to determine if Campylobacter spp. were introduced into the enlarged follicles after picking and became entrapped in the closed follicles during chilling. As shown in Table 1, more than $90 \%$ of follicles were closed even immediately after defeathering. These closed follicles remained closed $(85.5 \%)$ or opened again $(6 \%)$ after chilling. In contrast, only a low proportion of enlarged follicles became smaller or closed $(2.6 \%)$. These results suggested that most follicles became closed immediately after defeathering. Furthermore, the highest proportion of enlarged follicles that became smaller or closed after chilling was observed in the abdominal region, among the different areas of skin examined. However, the average Campylobacter spp. count was the lowest for the abdominal skin (Fig. 4). If the contamination mechanism proposed by Berndtson et al. occurred during processing, then the Campylobacter spp. count for the abdominal skin would have been higher than for other skin regions, suggesting that campylobacter species may not be confined to feather follicles as a result of the morphological changes occurring after defeathering 


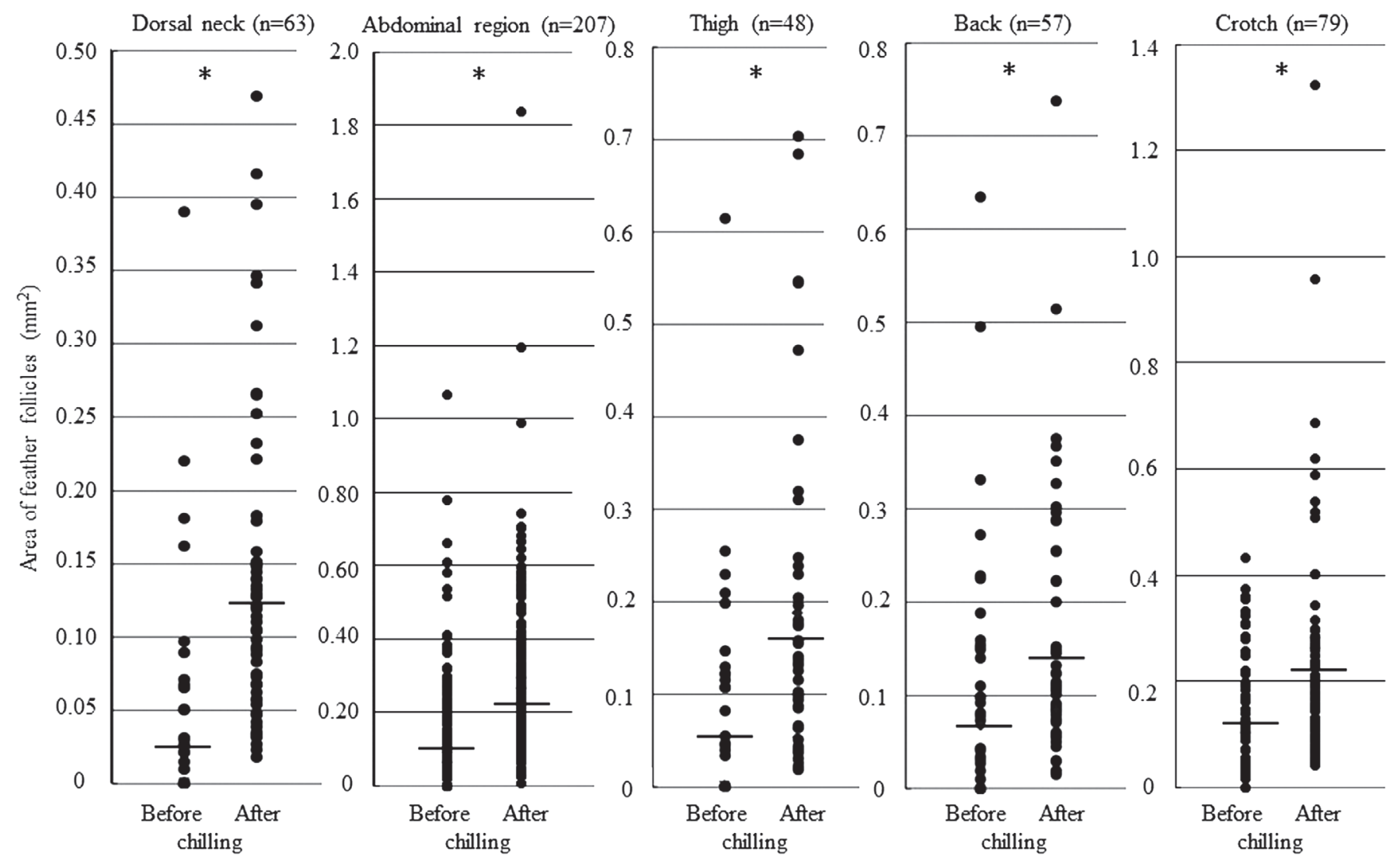

Fig. 3. Area of feather follicles after defeathering and after chilling. A total of 3,133 feather follicles of carcasses after defeathering and after chilling were photographed, and areas of the follicles were compared. The bar represents the average area of follicles examined. $* P<0.01$.

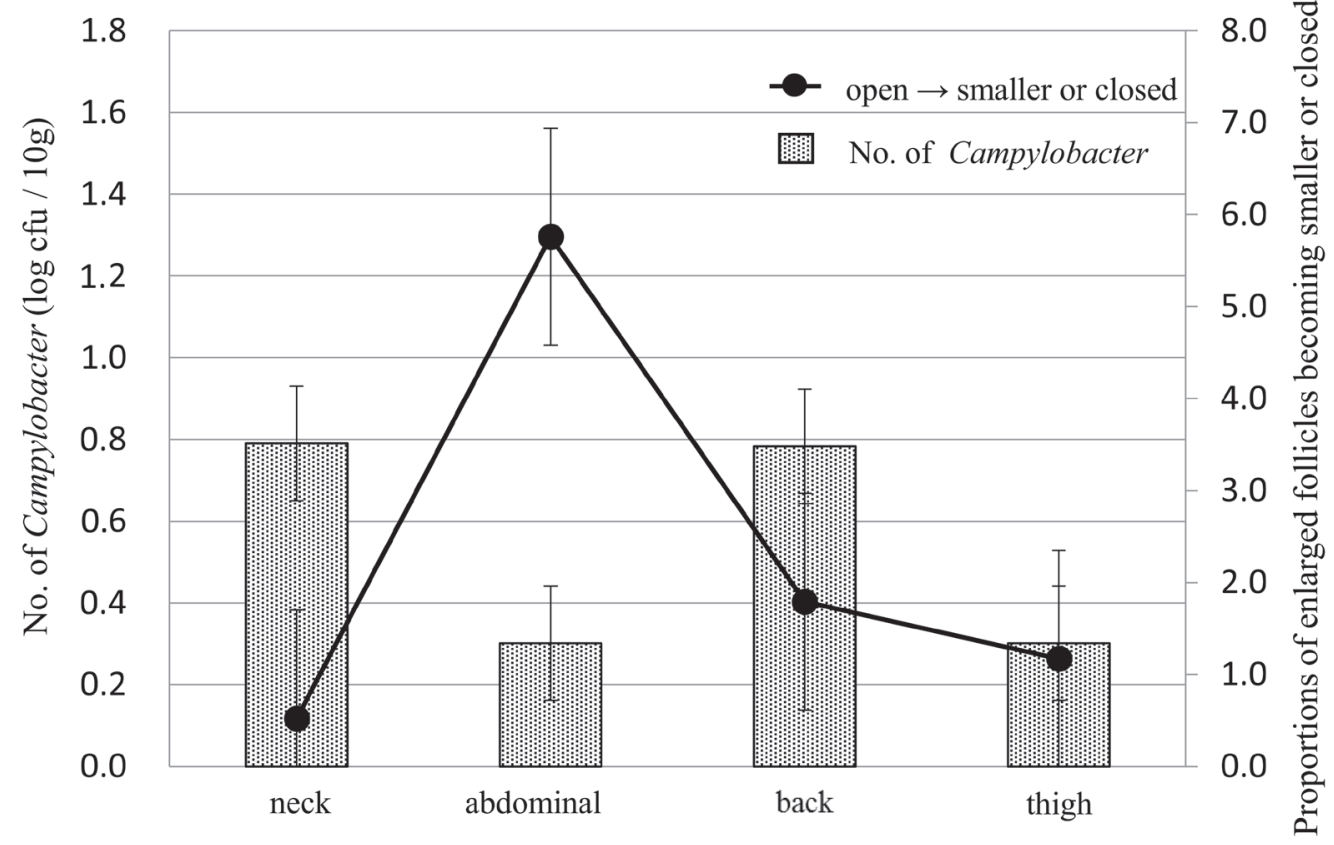

Fig. 4. Proportions of enlarged follicles that became closed and contamination by campylobacters in different skin areas of chicken carcasses after chilling. The number of contaminating campylobacter cells was determined by the MPN method. The number of Campylobacter represents the average from 3 chicken carcasses. 
and chilling.

Chantaraponot et al. [5] examined the location of C. jejuni on chicken skin using green fluorescent protein (GFP)-labeled organisms. They reported that most viable cells were entrapped within feather follicles along with water, as well as in skin crevices. Since they inoculated a high number of GFP-labeled C. jejuni $\left(10^{8}\right.$ to $\left.10^{9} \mathrm{cfu}\right)$ on the outer surface of breast skin stored at $-20^{\circ} \mathrm{C}$ before testing, their results may not have been representative of fresh skin naturally contaminated with $C$. jejuni.

Although the role of feather follicles in the contamination of chicken carcasses by campylobacters during processing is still debatable, further investigation is needed to determine whether the feather follicles of birds are able to open and close in response to physical factors including temperature, even in the postmortem period.

ACKNOWLEDGMENTS. The work was supported by grants for a project on global human resources and prevention of livestock epidemics by the Center for Animal Disease Control, University of Miyazaki, and the Ito Foundation (2016).

\section{REFERENCES}

1. Berndtson, E., Tivemo, M. and Engvall, A. 1992. Distribution and numbers of Campylobacter in newly slaughtered broiler chickens and hens. Int. J. Food Microbiol. 15: 45-50. [Medline] [CrossRef]

2. Berrang, M. E., Buhr, R. J., Cason, J. A. and Dickens, J. A. 2001. Broiler carcass contamination with Campylobacter from feces during defeathering. J. Food Prot. 64: 2063-2066. [Medline] [CrossRef]

3. Buhr, R. J., Berrang, M. E. and Cason, J. A. 2003. Bacterial recovery from breast skin of genetically feathered and featherless broiler carcasses immediately following scalding and picking. Poult. Sci. 82: 1641-1647. [Medline] [CrossRef]

4. Cason, J. A., Hinton, A. Jr. and Buhr, R. J. 2004. Impact of feathers and feather follicles on broiler carcass bacteria. Poult. Sci. 83: 1452-1455. [Medline] [CrossRef]

5. Chantarapanont, W., Berrang, M. and Frank, J. F. 2003. Direct microscopic observation and viability determination of Campylobacter jejuni on chicken skin. J. Food Prot. 66: 2222-2230. [Medline] [CrossRef]

6. Chen, X., Bauermeister, L. J., Hill, G. N., Singh, M., Bilgili, S. F. and McKee, S. R. 2014. Efficacy of various antimicrobials on reduction of salmonella and campylobacter and quality attributes of ground chicken obtained from poultry parts treated in a postchill decontamination tank. $J$. Food Prot. 77: 1882-1888. [Medline] [CrossRef]

7. Corry, J. E. and Atabay, H. I. 2001. Poultry as a source of Campylobacter and related organisms. Symp. Ser. Soc. Appl. Microbiol. 30: 96S-114S. [Medline] [CrossRef]

8. Enokimoto, M., Kubo, M., Bozono, Y., Mieno, Y. and Misawa, N. 2007. Enumeration and identification of Campylobacter species in the liver and bile of slaughtered cattle. Int. J. Food Microbiol. 118: 259-263. [Medline] [CrossRef]

9. Friedman, C. R., Neimann, J., Wegener, H. C. and Tauxe, R. V. 2000. Epidemiology of Campylobacter jejuni infections in the United States and other industrialized nations. pp. 121-138. In: Campylobacter, 2nd ed. (Nachamkin, I. and Blaser, M. J. eds.), ASM Press, Washington, D. C.

10. Friedman, C. R., Hoekstra, R. M., Samuel, M., Marcus, R., Bender, J., Shiferaw, B., Reddy, S., Ahuja, S. D., Helfrick, D. L., Hardnett, F., Carter, M., Anderson, B., Tauxe R. V., Emerging Infections Program FoodNet Working Group. 2004. Risk factors for sporadic Campylobacter infection in the United States: A case-control study in FoodNet sites. Clin. Infect. Dis. 38 Suppl 3: S285-S296. [Medline] [CrossRef]

11. Mangen, M. J., Havelaar, A. H., Poppe, K. P., de Wit G. A., CARMA Project Team. 2007. Cost-utility analysis to control Campylobacter on chicken meat: dealing with data limitations. Risk Anal. 27: 815-830. [Medline] [CrossRef]

12. Mead, G. C., Hudson, W. R. and Hinton, M. H. 1995. Effect of changes in processing to improve hygiene control on contamination of poultry carcasses with campylobacter. Epidemiol. Infect. 115: 495-500. [Medline] [CrossRef]

13. National Advisory Committee on Microbiological Criteria for Foods. 1997. Generic HACCP application in broiler slaughter and processing. J. Food Prot. 60: 579-604. [CrossRef]

14. Neimann, J., Engberg, J., Mølbak, K. and Wegener, H. C. 2003. A case-control study of risk factors for sporadic campylobacter infections in Denmark. Epidemiol. Infect. 130: 353-366. [Medline] [CrossRef]

15. Oosterom, J., Notermans, S., Karman, H. and Engels, G. B. 1983. Origin and prevalence of Campylobacter jejuni in poultry processing. J. Food Prot. 46: 339-344. [CrossRef]

16. Ruiz-Palacios, G. M. 2007. The health burden of Campylobacter infection and the impact of antimicrobial resistance: playing chicken. Clin. Infect. Dis. 44: 701-703. [Medline] [CrossRef]

17. Yamazaki-Matsune, W., Taguchi, M., Seto, K., Kawahara, R., Kawatsu, K., Kumeda, Y., Kitazato, M., Nukina, M., Misawa, N. and Tsukamoto, T. 2007. Development of a multiplex PCR assay for identification of Campylobacter coli, Campylobacter fetus, Campylobacter hyointestinalis subsp. hyointestinalis, Campylobacter jejuni, Campylobacter lari and Campylobacter upsaliensis. J. Med. Microbiol. 56: 1467-1473. [Medline] [CrossRef] 